\title{
Educational Project Management and Competitive Advantages of Educational Programs
}

\author{
Eleonora Nikitina $^{1 *}$, Marina Mikhailovna Borisova ${ }^{1}$, Aleksey Valerievich Kudryashov ${ }^{1}$, \\ Elena Begunova ${ }^{1}$, and Buyandalger Banzragch ${ }^{2}$ \\ ${ }^{1}$ Moscow City University, Institute of Education and Psychology of Education, Moscow, Russia \\ ${ }^{2}$ Institute of education of Mongolia under the Ministry of education, culture, science and sports, \\ Ulaanbaatar, Mongolia
}

\begin{abstract}
The article presents the study results of students' involvement in the transformation and development of intra-group interaction in the process of mastering an educational program. The key tool is students' project work aimed at solving significant educational problems. Project management in the educational program is based on distributed leadership. However, based on the results of surveys, interviews, and product analysis of students 'project activities, the problem of students' unwillingness to interact in the project group is revealed. The study purpose is to identify the impact of student engagement on the development of intra-group interaction in project groups. The correlation analysis has shown that students' lack of readiness for interaction correlates with a low level of their involvement in project activity, which leads to the process formalisation and project activity results. The solution to this problem gives the educational program competitive advantages due to the formation of students' competencies of interaction in project groups and distributed leadership.
\end{abstract}

\section{Introduction}

Educational organisations are searching for new ways to achieve competitive advantages in the market of educational services. Organisations offering new educational programs are interested in the long-term benefits that can be achieved based on the new project management methodology. This is why students ' project activities are so widely used, becoming the most important means of forming general professional competencies.

At the same time, research and teaching staff and students are beginning to perform new functions and roles for themselves by joining project groups. This is often accompanied by a weak involvement in group activities and an unwillingness to take responsibility for the overall result of the activity. To work effectively together on a project, group members must understand and accept the shared values of the group and educational activities and show interest in the common cause. Such values are the values of education and pedagogical activity, the desire to improve educational activities. At the level of the individual, creativity

* Corresponding author: nik2211@mail.ru 
and initiative based on responsibility to the group become the most important values [1,2]. At the organisational level, this is team building and leadership. The study purpose was to understand how the involvement of each student in project activities affects the development of intra-group interaction for better development of the undergraduate educational program.

The Actor-Network Theory (ANT) developed by B. Latour was used as the theoretical basis of the research [3]. In this context of this theory, basic research concepts were defined. Project management was applied to educational programs as a whole and its components. The presented research presents new aspects of project management of interaction as an element of the educational program implemented in the educational and research work of the students. This interaction is of a research nature and is understood as an element of the educational program implemented in the educational research and research work of students. It is a joint activity, a dialogue of all subjects involved in the implementation of the educational program for the interpretation and conceptualisation of the studied facts and phenomena.

\section{Methods}

The research was conducted based on surveys, interviews, and analysis of project products of pedagogical university students enrolled in undergraduate educational programs with a total number of 251 people. Correlation analysis was used to study the relationship between student engagement and interaction in project groups. Two metric variables were determined on the same sample, where the Pearson coefficient showed a linear relationship between the two features.

The study was conducted in stages. At the first stage, theoretical approaches of pedagogy, sociology and social psychology in the field of involvement, team building and research interaction in project groups were studied. At this stage, significant research B. Latour, M. Skriven, R. Paul. This allowed us to form the working concepts of the study and build a hypothesis. At the next stage, surveys and interviews were conducted with undergraduate students who worked on various educational projects in the process of mastering academic disciplines and practices. The questionnaires and interviews were developed using a fivepoint Likert scale. The groups discussed the following issues: what difficulties one faces, what helps successfully solve problems that arise during the formation of general professional competencies, what helps one change their work for the better, and what values guide in working together. The data obtained were analyzed using correlation analysis. This analysis revealed the relationship between student engagement and the development of intra-group interaction. Qualitative analysis of the responses showed that many students understand the overall values of the group, but in project groups show low creativity and initiative. Analyzing the projects developed by students according to the modules of the educational program, it was found that the project as a result of collective work often does not have sufficient novelty and originality. Interesting ideas were expressed, but during the joint work, it was not possible to agree within the group and develop a new approach. Most often, students agreed with the proposal of the project team leader, did not demonstrate a desire to promote their ideas, agreeing with the opinions of people who were important to them, because of this, the project product did not contain anything new but used well-known data. The main idea that was promoted in the students' educational projects: how to change the school for the better, was not properly developed. If undergraduate students, developing a group educational project, offer a new project product that is used in practice in educational organisations, then this creates competitive advantages for the educational program in which they study. As a result, enrollment for this program will grow, and students themselves are successfully employed after the final certification of the educational program. 


\section{Results}

The revealed relationship of students' involvement in the transformation and development of intra-group interaction during the development of the educational program allows influencing the competitive advantages of the educational program. In the logic of research, it is necessary to create project portfolios based on the modules of the educational program. Thus, to ensure the promotion of the best project products in the market of educational services, using the potential of educational and industrial practices. As well as transform the procedures for the final exam in the educational program. Distributed leadership in project groups allows overcoming resistance to change and low involvement of students in project activities. To do this, it is necessary to concentrate resources on problematic areas of project activity for a specific educational program and give the initiative to creative leaders. As soon as the number of students involved in project activities exceeds the norms of statistical distribution, other students will begin to join. Thus, at the final stage of the study, two portfolios of educational projects were formed - projects that work for the development of project and leadership competencies of students, and projects that work for the improvement of school teaching.

\section{Discussion}

The course and results of the presented research are in the context of transforming educational practices based on project management by influencing the involvement of students in this process. These issues were addressed by M. Young, emphasising the values of education and the need for full involvement of highly educated people in various social practices that ensure the development of society [4]. Currently, students of the pedagogical university have the necessary resources to transform educational practices and improve the performance of schools. The mechanism that triggers this process is project management. His best theory and practice is presented in the project management knowledge base [5]. However, educational projects that have specific characteristics are not presented in this collection. This study specifies some practical aspects of educational projects $[6,7]$.

The theory of B. Latour focuses on the sociality of new knowledge and interaction, which acquires a new value in the context of the educational system. This system is currently designed not only to transmit knowledge and provide new generations with cultural and historical knowledge but also to produce new knowledge, work to update and transform educational practices $[8,9,10]$. Within the framework of educational programs, new educational practices are emerging that change the perception of the educational system.

\section{Conclusion}

Educational project management ensures the competitiveness of educational programs by enabling students to understand and accept the values of education. By engaging in research interaction, students create educational projects that transform educational practices. New roles and positions in the project group allow purposefully developing creativity and initiative of students, involving them in solving the most important education problems. These innovations are implemented in the context of higher education marketisation [11-14]; this has become a global trend in many countries.

The way educational services are provided and managed is changing, including the way, teaching practices are managed to solve problems of competitive educational programs. These programs bring innovative components to school life practice [15]. The study results 
complement the data on the impact of distributed leadership on teacher job satisfaction and self-efficacy. Training future teachers in ways to interact and collaborate leads to this effect.

\section{References}

1. E.K. Nikitina, E.V. Gakova, European Scientific Journal 10(8), 259-264 (2014)

2. E.K. Nikitina, O.A. Lyubchenko, Modern problems of science and education 4, 185 (2015)

3. B. Latour, Reassembling the Social (Publishing House of the Higher School of Economics, Moscow, 2014)

4. M. Yong, The Rise of the Meritocracy, 1830 - 2033 (Pelican book, London, 1961)

5. A.N. Pavlov, Project management based on the PMIPMBOK ${ }^{\circledR}$ standard. Methodology presentation and application experience (Knowledge Laboratory, Moscow, 2017)

6. R. Subramanian, M.A. Demoss, Case Studies in the Environment 2(1), 1-7 (2018)

7. B.F.M. Olechnowski, The American Biology Teacher 79(6), 455-459 (2017)

8. L. Vos, S.J. Page, Academy of Management Learning \& Education 19(1), (2018)

9. H. Aguinis, Performance management (Chicago Business Press.Google Scholar, Chicago, 2019).

10. H. Aguinis, R.S. Ramani, N. Alabduljader, J. R. Bailey, J.A. Lee. Pluralist Conceptualization of Scholarly Impact in Management Education: Students as Stakeholders. Academy of Management Learning \& Education 18(1) (2019)

11. D.V. Banker, K.T. Bhal, Creating world class universities: Roles and responsibilities for academic leaders in India. Educational Management Administration \& Leadership 48(3) 570-590 (2019)

12. E.C.K. Cheng. Knowledge management for improving school strategic planning. Educational Management Administration \& Leadership 1-8 (2020)

13. Y. Liu, M. Şükrü Bellibaş, S. Gümüş. The Effect of Instructional Leadership and Distributed Leadership on Teacher Self-efficacy and Job Satisfaction: Mediating Roles of Supportive School Culture and Teacher Collaboration. Educational Management Administration \& Leadership 1-10 (2020)

14. L. Thomas, M. Tuytens, G. Devos, G. Kelchtermans, R. Vanderlinde, Educational Management Administration \& Leadership 48(1), 106-132 (2018)

15. J.E Morris, G.W. Lummis, G. Lock, Educational Management Administration \& Leadership 1-9 (2019) 